\title{
ASPECTOS DE LA SENTENCIA DEL TRIBUNAL DE LO CONTENCIOSO ADMINISTRATIVO (*)
}

\author{
ADOLFO GELSI BIDART \\ Profesor Titular de Derecho Procesal de la \\ Facultad de Derecho y Ciencias Sociales de \\ Montevideo
}

SUMARIO:

1) Delimitación temática: 1) Lo sustantivo y lo procesal. 2) Cuestión, órgano y proceso. 3) Enfoque procesal. - II) Situación del Tribunal uruguayo: 4) Ubicación. 5) Situación orgánica. 6) Actos afectados. - III) Elementos de la sentencia: 7) Voluntad. Capacidad. Legitimación. 8) Lugar, Tiempo, Forma. 9) Antecedentes: A. En el proceso. B. Fuera del proceso. 10) Objeto. Causa. 11) Condición. (Consumación del acto). IV) Naturaleza de la Sentencia: 12) Punto de vista subjetivo. 13) Sentencia. 14) Aspecto objetivo. - V) Efectos: 15) Generalidades. Límites subjetivos. 16) Límites temporales. 17) Límites objetivos: A. Cuestión decidida. B. Declaración, condena, constitución. C. Nulidad.

\section{I}

\section{Delimitación Temática}

1) Los problemas de lo contencioso administrativo abarcan (como todas las cuestiones a que se refiere el Derecho Procesal) una vertiente sustantiva o de fondo, y otra adjetiva, correspondiendo la primera al Derecho Administrativo y al Derecho Procesal la segunda. - En sentido lato, aquella disciplina estudia también ciertos aspectos de procedimiento que corresponden, "- desde el punto de vista de las facultades de los administrados - a los recursos que se plantean en el ámbito de la administración misma.

Cuando se pasa de ésta a la justicia, ingresamos en el campo procesal, para el cual rigen las categorías habituales de esta disciplina.

Corresponde, en consecuencia, separar los temas propios del D. Administrativo. - Especialmente: a) Noción de administración, de acto

(*) Ya publicada en la "Revista de la Facultad de Derecho de México", como contribución al homenaje a Pedro Calamandrei, tomo VI, octubre-diciembre 1956, N.o 24, págs. 253-74. 
(y de hecho) administrativo y demás conexas (funcionarios, órganos, etc.), b) Límites de lo contencioso - administrativo, sea desde el punto de vista de los sujetos (v. gr.: ¿las personas públicas no estatales, ingresan en su ábito?), sea en relación con el objeto. - Es decir si no basta la calidad administrativa de los sujetos (o de algunos de los sujetos) intervinientes y debe tener naturaleza especial, la cuestión disputada, fundamnetalmente en cuando al tipo de normas que la rigen; lós actos sometidos a la norma común, - de manera particular de Derecho Privado -, no ingresarían, en tal caso, en su órbita. c) De "jure condendo", relación entre el órgano jurisdiccional y el administrativo: posibilidades y alcance de la fiscalización de la actividad de éste por parte de aquél. - Tema que entronca directamente en el Derecho Constitucional: separación de poderes del Estado; constitución de órganos al margen de los diversos poderes clásicos; "distribución" de las funciones jurídicas consideradas públicas, entre los diversos organismos aludidos. - Como consecuencia, d) Diversas especies de lo contencioso - administrativo, etcétera. (1).

2) Instaurado un sistema eñ un régimen jưrídico positivo, el Derecho Procesal no tiene que delimitar la "cuestión" contencioso administrativo que se plantea ante determinados Tríbúnales, del mismo modó que no le corresponde decidir acerca de la de nátưráleźa civil, penal, comercial, laborál, etc., que llega a los estrádos judíciáles. Es una materia propia del Derecho Administrativo, que habra de resolverla junto con otras tales como: vía administrativa previa; necesidad y modos de su agotamiento; conexión entrè lấ vía adminisistrativa y la judicial, etc., sin olvidar las ya enunciadas. (2).

bebilus

Al Derecho Procesal incumbe, según la tradicional distinción, el aspecto orgánico y el procesal propiamente dicho o formal, de la llamada vía judicial o jurisdiccional (3). - Por una parte, órganos jurisdiccionales, integración y competencia (4). Por la otra, procesos argue da lugar la cuestión contencioso-administrativa, en sus diversos aspectos, ordenatorios o procedimentales y en el estudio de los actos procesales y su eficacia en y fuera del proceso.

til Ver un desarrollo de los principales problemas antes de la Constitución de 1952, en Couture, "Curso del Código de Organización de los Tribúnales", Móntevideo, 1936, tomo"1 (único), págs. 227-253.

(2) Para un estudio de conjunto del problema en el sistema uruguáyo v. Aparicio Méndez, "Lo Contencioso de Anulación en el Derecho uruguayo (Montevideo 1952) y E. Sáyágës Laso, "El Tribunal de lo Contencioso-Administrativo". (Montevideo 1952). - También Hugo Pereira Anabalón "Régimen jurídico" del Tribunal de to Contencioso-Administrativo (én "La

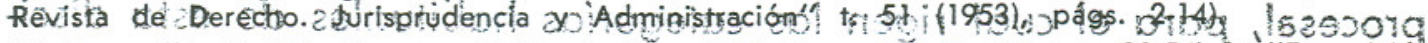

(3) V. en "La Justicia Uruguaya" (Montevideo 1955, tomo 3.0, Doctrina p. 39-54) la "Exposición

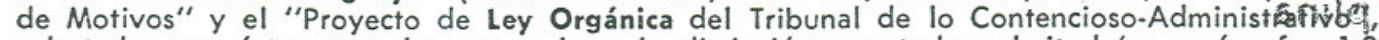
redactados por éste, y en lo que se hace la distinción con toda pulcrịtud (v. parágrafos 1-2

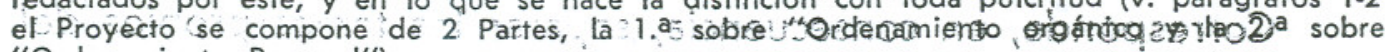

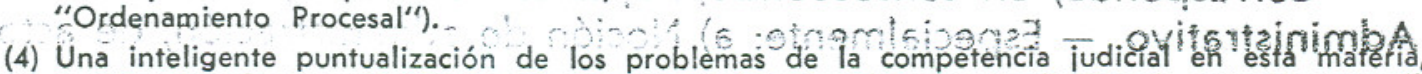
en "Barrios de Angelis "La Competencia Contencioso-Administrativa" ("La Justicia.Uruguaya"., Montevideo 1956, t. 34, Doct. p. 19-26hseñalando diversos regímenes spexistentes (justicia or-

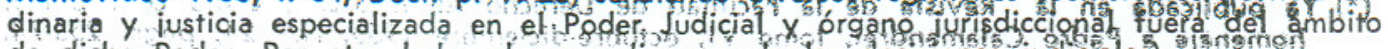
de dicho Poder. Por otro lado, alcances diversos de las decisiones iudiciales). 
Como es lógico, habrá zonas parcialmente comunes. Otras que incluso en esa delimitación genérica, correspondan al Derecho Administrafivo aunque puedan ser estudiadas, además de por éste, por el Derrecho Procesal ("accessorium sequitur. r's)icomo las funciones administrativas confiadas a los Tribunates: - Además en esta materia (en buena medida como en el Derecho Procesal aplicado a las cuestiones penales en la mayor parte de los regímenes positivos, entre ellos el uruguayo), prácticamente la parte mayor de la ejecución de las sentencias quela asignada a la misma Administracićn: punto delicado y básico para la efectividad dei Derecho, es determinar medios para que pueda alcanzarse. - Por las apuntadas razones normalmente no será el Derecho Procesal el llamado a establecerlos.

3) Nuestro tema es un enfoque procesal de algunos problemas relativos al acto procesal básico, la sentenciá (definitiva), correspondiente a uno de los órganos jurisdiccionales que entienden en lo contencioso-administrativo en el Uruguay.

Por tanto, como surge de lo anterior, son supuestos los temas y conceptos del Derecho Administrativo correspondientes y se procura aplicar ciertas nociones procesales a la misma, para ubicar ta sentencia de determinado órgano (Tribunal de lo Contencíoso - Administrativo) en una materia delimitada por ta Constitución (actos administrativos presuntamente ilegales) para cumplir una actividad determinada, con eficacia, en dicho ámbito (confirmar, ratificar en forma defínitiva o anular el acto supuestamente ilegal).

$$
\text { II }
$$

\section{Situación del Tribunal urưguayo}

4) A los efectós de estas notas basta ubicar ál fribunat encel conjunto de las posibitidades de lo contenciosos administrátivo (de tás que sóla te tha correspondido una porción redativamente modesta) y entre los diversos órganos que administran justicia èn nuestro país (5).

5) Em cuanto a segundo aspecto el sistema consagrado confempla la objeción de la orfódoxia en fa separación de poderes. Niñge no podría, seguiu ésta, invadir la esfera de ofro y más concrefamente, introducir variantes en sus actos. Las soluciónes en consecuencia, po-

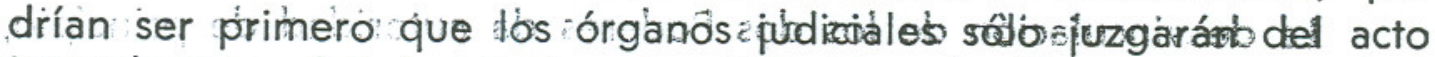

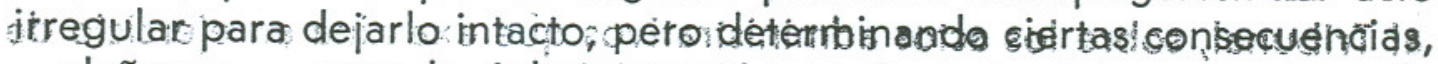

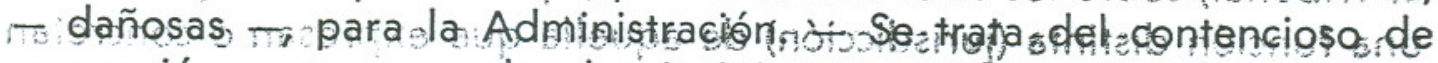
reparación, que responde al principio universol en $\mathrm{Derechor}$ desflye

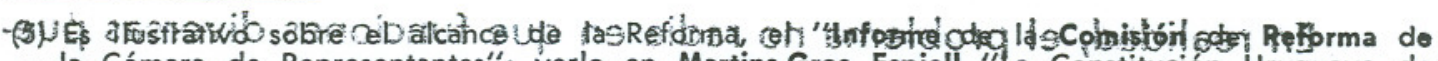

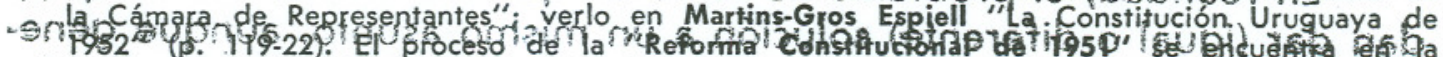

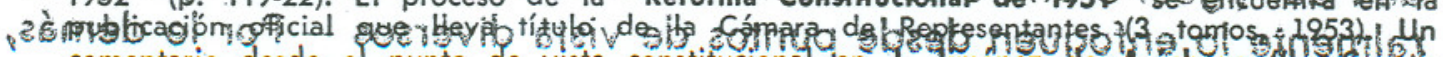
comentario desde el punto de vista constifucional en . Jméne de Arechaga La Consti-

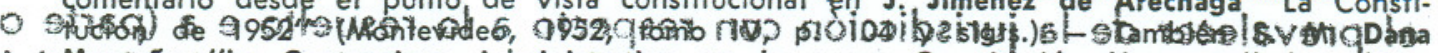

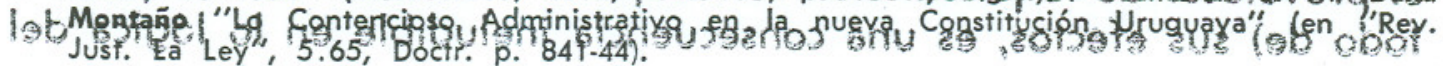


quien causa un daño anti - jurídico, debe responder del mismo. - El Derecho moderno (de las naciones civilizadas) ha procurado, por diversos medios, la efectiva aplicación del principio a los actos irregulares del Estado. - $\mathrm{O}$ bien segunda solución, entregar a un organismo incluído en los cuadros de la Administración Pública, el juzgar del acto impugnado para reformarlo, confirmarlo o anularlo, de manera similar a lo establecido en Francia con el Consejo de Estado.

La Constitución de 1952 y la ley uruguaya, sólo parcialmente dan intervención al Tribunal en la reparación por acto administrativo irregular, distribuyendo esta materia entre aquél y la justicia ordinaria. Cuando se trata de la posible anulación del acto el Tribunal tiene competencia privativa y originaria que eventualmente podrá no ser tal, si una ley ulterior crea "órganos inferiores dentro de la jurisdicción contencioso - administrativa", art. 320 inc. 1 de la Constitución.

Este Tribunal carece de todo vínculo tanto con la Administración como con el Poder Judicial constituyendo un ejemplo más de la ruptura que el Derecho Constitucional moderno ha provocado en los marcos rígidos de los tres Poderes clásicos. - Para citar algunos ejemplos, la Constitución uruguaya coloca al margem de los mismos además del mencionado, al Tribunal de Cuentas, al Consejo de la Economía Nacional (aún no creado) y la Corte Electoral, sin contar con la floración de Entes Autónomos en el ámbito administrativo nacional y municipal.

El Tribunal de lo Contencioso - Administrativo es un órgano al que corresponde primariamente ejercer la "función jurisdiccional" - (art. 307 , inc. 2), pero que no integra el Poder Judicial. - Se trataría de una jurisdicción especial e independiente, por oposición a la ordinaria, sea o no especializada, que corresponde a aquel Poder. - Por tratarse del órgano supremo en la materia (a la vez que único) se toma como modelo para diversos aspectos de su organización la Suprema Corte de Justicia, órgano superior del Poder Judicial (calidades, formas de designación, prohikiciones, incompatibilidades, dotación, duración del cargo, art. 308) y transitoriamente se le aplican algunas disposiciones que rigen para la $S$. Corte en lo que se refiere a funcionamiento plazos para expedirse, etc. (Disp. Trans. letra N), en tanto no se promulgue la Ley Orgánica del Tribunal.

La desvinculación de los dos Poderes da autoridad de princípio, al Tribunal, sobre los actos administrativos que examina en ejercicio de una función distinta (jurisdicción) de aquella que expresan o concretan (función administrativa).

En realidad, el problema no radia en que funciones diversas pue. dan dar (igual o diferente) solución a un mismo asunto, aunque generalmente lo enfoquen desde puntos de vista diversos - Por lo demás, el prevalecer de la jurisdicción con respecto a lo resuelto e a (parte o todo de) sus efectos, es una consecuencia ineludible en lo lógica del 
sistema jurídico, pues se trata de la actividad encargada de determinar la solución jurídica del caso concreto; planteado el problema en tales términos (cuál es la solución de derecho) resolverlo corresponde en exclusividad a la jurisdicción.

Tratándose de un órgano supremo en el ámbito de su actuación y, a la vez, independiente ed los dos Poderes, no hay dificuldad en admitir la posibilidad de que modifique el acto administrativo. - Por otra parte, se podrá reconocer que señala (con mayor o menor significación) un cauce a la actividad del Poder Judicial, imponiendo, pri. mero, la precedencia de su intervención y una vez dictada la sentencia, la eficacia de la misma, pasada en autoridad de cosa juzgada.

6) Si bien en principio toda actividad de la Administración podría ingresar en la zona* de lo contencioso - administrativo, el aspecto primordial corresponde a los procesos a que dan lugar los actos administrativos. - Esta es la esfera reservada al Tribunal $y_{\text {, }}$ por ende, los juicios (v. gr.) por daños y perjuicios por el hecho de los funcionarios, siguen tramitándose ante la Justicia de Hacienda especial $u$ ordinaria, que integra el Poder Judicial.

Con respecto del acto administrativo debe estudiar su legalidad, para declarar: a) su confirmación pura y simple; b) su confirmación, reservando al perjudicado la acción de reparación; c) su nulidad o inaplicación en el caso concreto; d) su nulidad "erga omnes".

Además se le ha atribuído competencia exclusiva en los conflictos (contiendas o diferencias) que se promuevan entre organismos públicos o entre los integrantes de los mismos, en el segundo caso "siempre que no hayan podido ser resueltos por el procedimiento normal de la formación de la voluntad del órgano" (art. 313, inc. 2). Su recordada situación autónoma frente a todos los demás organismos públicos del país, su jerarquía y la función jurisdiccional que le compete, facilitan esa actuación.

III

\section{Elementos de la sentencia}

7) Procede examinar a grandes rasgos, los principales requisitos, caracteres o elementos, propios de lá sentencia del Tribunal, advirtien. do que en su mayoría siguen las condiciones generales, por lo cual solo corresponde señalar alguna particularidades.

Así no hay variantes de Trascendencia en materia de voluntad y de capacidad, remitiéndose la ley a los principios del Derecho Positivo vigente para los demás actos judiciales; en algunos casos, con respecto a la Suprema Corte de Justicia (capacidad, en el sentido de que se requiere determinada edad para ingresar a los cargos respectivos).

En cuanto a la legitimación, caben, algunas precisiones. - Nc 
hay problema en cuanto al órgano en sí, punto de vista de la competencia, porque ésta es originaria y exclusiva - En cuanto a ta integración, por tratarse de sentencia definitiva, habrá de aplicárse la disposición igual a la que rige para la Suprema Corte de Justicia: cinco miembros presentes, art. 310 Constitución; cfr. 123 C. Organización).

El quorum de votantes varía, segứn la solución que se adopte. - La -disposición constitucional está inspirada en to que podría llamarse un criterio conservador para el acto administrativo cuando se alega la lesión de un interés y al contrario si es lesionado un derecho subjetivo. Al Las soluciones son: a) lesión de derecho subjetivo: la nulidad puedé declararse por simple mayoría $(3)$; b) lesión de un interés directo personal y legítimo: se requieren 4 votos conformes, pero bastan 3 por la nulidad, para reservar a la parte demandante la acción de reparación (a. 310 ). En este caso la mayoría debe ser especial para declarar "suficientemente justificada la causal de nulidad invocada" (a. 3j:0, inc, 3) pero justamente porque se da menor trascendencia a la reparación que a la anulación, el órgano por mayoría simple (tres votos) puede, - en el mísmo acto -, reservar la acción respectiva.

8) Nada de particular, tampouco, con relación al lugar. La sede det Tribunal es en Montevideo y su competencia, nacional. Los principales problemas relativos al tiempo en el proceso contencioso-administrativo se refieren a los plazos para interponer la acción de nulidad ante el Tribunal y el nexo con el procedimiento ante la Administración, antecedente del proceso jurisdiccional; el plazo para dictar sentencia es el mismo establecido para la S. Corte, por expresa determinación constitucional (Disp. Trans. letra N) ap. $3{ }^{\circ}$ ).

Igual remisión en el problema de la forma; que carece de especiales determinaciones. Esta general coincidencia de las soluciones de la justicia ordinaria con ésta, especializada e independiente de todo Poder, subraya de manera expresiva el régimen directamente jurisdiccional elegido por el Constituyente (6).

9) En cuanto a los antecedentes de la sentencia, desde el punto de vista del proceso sólo podemos remitirnos al conjunto de los actos procesales que la preceden sin realizar la (necesaria) discriminación entre los que son simples antecedentes en el tiempo y aquéllos que,

(6) Las soluciones del Derecho Procesal común inspiran las normas constitucionales vigentes, al igual que el "Proyecto de Ley Orgánica" citado (nota 3) que encuentra su complemento doctrinario adecuado en la "Exposición de Motivos". correspondiente. - La unidad en las dispósiciones, responde a tá unidad de concéptos, que debe comprobarse como un hecho y recomendarse como adecuada; se trata de la misma materia, aunque especializada y las diferenciás radican en ta necesidad de una adaptación que - en el problema del proceso de conocimiento :- reviste mínimas exigencias. - En tal sentido, Prieto Castro ("Tratado de Derecho Procesal", I, 1952) señala que "el derecho positivó (español)... sigue (aquí) fúndamentalmènfe Slas huellas del D. Procesal común" $y$ en docfrina indica que esta "manifestación del procesa.... no puede oponerse... a las otras dos, penal y civil, sino que próplamente es uná hijuela de éste" (p. 43). E insiste en que "las posibilidades de unificación son aquí casi absolutas" recusando como "primito diferenciador del eniuiciamiento de... organismos públicos" la existencia de leyes procesales especiales y de Tribuna. sles contencioso administrativos :"donde figura representada la Administración" (p. 44, nota 59j, cosa que, subrayamos, no ocurre en el Tribunal urúguayo. 
por imprescindibles para que pueda dictarse la sentencia, constituye verdaderos presupuestos del acto, en el sentido de Carnelutti (7). No se entra aquí al análisis porque las soluciones no son diversas de las que corresponden en el Derecho Procesal común.

A - No obstante, cabe señalar (por su particularidad), el dictamen del Procurador del Estado en lo Contencioso - Administrativo, que deberá preceder en todo caso, a la sentencia del Tribunal; el referido órgano "será necesariamente oído, en último término, en fodos los asuntos de la jurisdicción del Tribunal" (art. 315 inc. 2).

Puede compararse al Procliador del Estado, por la función que ejerce ante el Tribunal, con el Fiscal de Corte, que actúa ante la Supremá Corfe de Justicia, pero con dos salvedades principales que contribuyen a deslindarlo. En primer lugar, la actuación del Procurador del Estado es ineludible en todos los asuntos que se tramiten ante el Tribunal y por onde su dictamen es, en todos ellos, antecedente necesario de la sentencia, no así el dictamen del Fiscal, que debe ser oído necesariamente sólo en los casos expresamente previstos por la Ley Orgánica de la S. Corte (de 28-X-1907). Con todo, la diferencia es más aparente que real pues la ley cit. (art. 11) también establece que el Fiscal de Corte "deberá ser oído en todas las causas de jurisdicción originaria de la Alta Corte" y, cabalmente, el Tribunal, en tanto no se creen organismos subordinados, sólo tiene competencia originaria.

La segunda observación a tener en cuenta, es que el Fiscal de Corte, como integrante del Ministerio Público, puede actuar como parte procesal en sentido estricto, al menos formal (sea como actor, reo o tercerista en el juicio) o bien como "auxiliar del juez" (C. Proc. Civ. art. 175 y C. Organización art. 136). En el último caso, se limita a expresar su opinión como técnico en derecho, una suerte de "perito" jurídico que formula su dictamen para ilustración del Juez (8).

Este es el modo de actuar permanente del Procurador del Estado. La autoridad demandada "podrá hacerse representar o asesorar por quien crea conveniente" (art. 316) y el Procurador, "independiente en el ejercicio de sus funciones", "puede en consecuencia dictaminar según su convicción, estableciendo las conclusionés que crea ar:regladas a derecho" (art. 315 inc. 2). Por ende, su dictamen considerado desde el punto de vista de. la sentencia, es necesario en su emisión (problema de correlación o de ordenación temporal en el

(7) Carnelutti "Sistema del Derecho Procesal Civil" (Trad. Alcalá-Sentís IIT, p. 550) entiende por presupuesto (del acto) "un evento distinto del acto procesal y anterior al mismo, del que depende, en todo o en parte, su eficacia". "No basta la vinculación de varios actos en el procedimiento", pues los hay "independientes de un acto anterior y otros, dependientes del mismo": sólo éstos últimos son presupuestos.

(8) De Maria "Lecciones de Procedimieno Civil" (Montevideo 1925) señalaba que en estos casos la intervención del Ministerio Público "se reduce a dar su parecer o dictamen, en forma de conclusiones, antes de la sentencia" (pág. 217), emitiendo su dictamen, "para ilustrarlo" al Juez (p. 212), opinión que puede considerarse universal en la doctrina. Ver, por ej. Chiovenda "Principios de Derecho Procesal Civil". (trad. Casais y Santa 10. p. p. 562): "por via de requisitoria o de dictamen, el M. P. obra, no como parte litiganfe, sino como representante del interés público en un asunto que se ventila entre otros y en los de iurisdicción voluntaria". "au 
proceso) pero sólo facultativo en cuanto a la solución a dar al fondo del asunto. En otros términos, la sentencia no está atada en el pronunciamiento (parcial o total) que debe formular, por el que hubiera establecido el Procurador, al revés de lo que ocurre en el caso de los peritos decisores o arbitradores en la materia de sua dictamen; lo contrario hubiera significado, prácticamente, transferir las funciones del Tribunal al Procurador del Estado.

La Comisión de Constitución de la Cámara de Representantes (Informe en mayoría) al realizar "el "Análisis de los Arts. modificaque es, será oido en todos los asuntos de la jurisdicción del Tribunal dos", dijo que el Procurador del Estado, "como asesor de la legalidad en último término. Podrá así contribuir con sus dictámenes, a orientar la jurisprudencia del Tribunal" (9) lo cual explica la necesidad de su informe y "la posición de superior imparcialidad que debe mantener el titula de la procuraduría, quien ha de actuar con serenidad de magistrado", como "mero defensor del derecho y no de una parte determinada" (10).

B - Si vamos más allá del proceso judicial, nos encontramos con un antecedente que se establece (por la Constitución) como necesario para el proceso contencioso - administrativo: el haberse efectuado un acto administrativo definitivo (art. 309).

A su vez, la definitividad del acto, desde el punto de vista del impugnante y con relación al proceso a que aludimos, se configura una vez "agotada la vía administrativa, mediante los recursos correspondientes" (art. 319). En otros términos, antes de acudir a la justicia contencioso - administrativa, debe el agraviado interponer todos los recursos que corresponden en el ámbito de la propia administración.

La existencia de tal acto administrativo o, más ampliamente, la realización de un (pretendido) acto administrativo (definitivo), ¿es un precedente necesario para el proceso (presupuesto procesal) o para la sentencia definitiva sobre el fondo del asunto? La misma pregunta se hace, a veces, con referencia a la pretensión del demandante $u$, homólogamente, a la sentencia favorable sobre el fondo del asunto. El problema se plantea con respecto al procedimiento administrativo - "al agotamiento de la vía administrativa (11).

Por nuestra parte entendemos, en primero lugar, que el antecedente o presupuesto lo constituye el acto administrativo (impug-

(9) "Reforma Constitucional de 1951", I. p. 668.

(10) A. R. Real "Posición imparcial que debe mantener en el juicio anulatorio la Procuraduría del Estado en Contencioso administrativo" (en "La Justicia Uruguaya", tomo 32, págs. 395 y 394).

(11) El Tribunal de to Contencioso-Administrativo ha realizado diversos pronunciamentos sobre el punto. En uno de ellos, (Moretti redactor) dijo: "Los actos administrativos adquieren el carácter de definitivos cuando la autoridad administrativa se ha pronunciado ex. presa $\circ$ implícitamente sobre los recursos deducidos". "El procedimiento administrativo constituye un presupuesto procesal, en cuanto de su verificación depende que el órgano jurisdiccional pueda hacer un pronunciamiento sobre el fondo, 0 en cuanto de su existencia depende el ejercicio de la acción de nulidad" (Sentencia de 29 XI 1954, en "La Revista de Derecho, Jurisprudencia y Administración", tomo 52 (1954), pág. 259). 
nado), más que el procedimiento administrativo (consumado) o, encarado desde el punto de vista del recurrente, el haber agotado los recursos puramente administrativos. En realidad esta circunstancia produce un aspecto del acto pues le confiere la calidad de definitivo, sin la cual no corresponde, jurídicamente, plantear su impugnación.

En segundo término, ¿de qué sería presupuesto el acto referido? Couture distinguía en los presupuestos: a) los presupuestos procesales en sentido estricto, que asegurarían la existencia del proceso (como jurisdicción del juez y capacidad de las partes), (12); b) los de la pretensión (ejis; vigencia o no caducidad del derecho; su titularidad; validez de la representación; agotamiento de la vía administrativa); c) los de validez del proceso, o sea, la regularidad de los actos procesales; d) los de la sentencia favorable (ejs: prueba de los hechos conocimiento del derecho que apova la pretención) (13).

En el caso, entendia que el agotar la vía administrativa constituía presupuesto de la pretensión, en el sentido de que la pretensión (para ante la jurisdicción) no podía (jurídicamente) surgir y plantearse, antes de haberse consumado los recursos administrativos. Tal circunstancia no obsta al surgimiento del proceso, como lo demuestra en nuestro derecho (14) el que recién la sentencia definitiva pueda declarar esa omisión; ni a la regularidad de los actos; ni influye en el dictado de una sentencia que acoja la pretensión del demandante (sentencia favorable): ("quedamos, pues, por eliminación, con que el agotamiento de la vía administrativa constituye un presupuesto procesal de la pretensión (15).

Debe acotarse, en cuanto a este interesante planteo que por virtud de la conexión entre los poderes de las partes (acción) y del juez (jurisdicción), o de lus actos de unas y otros (primordialmente demanda y contestación por un lado y sentencia), las conclusiones que enfoquen a las primeras podrán (con las debidas adaptaciones) aplicarse al segundo; Así, por ej., el presupuesto de la pretensión, lo será también de la sentencia sobre el fondo del asunto.

De donde, es importante recurrir a la distinción entre forma y fondo, para señalar el alcance de tales antecedentes y mencionar los presupuestos formales, o de admisibilidad de la demanda, o de una sentencia sobre el fondo. - Y además los presupuestos que atañan al asunto de fondo, o de fundabilidad de la demanda, de proceden-

(12) Couture "Fundamentos del Derecho Procesal Civil", 2.a edición, p. 46.

(13) Couture "El agotamiento de la via administrativa como presupuesto procesal" (en "La Revista de Derecho, Jurisprudencia y Administración", tomo 52 (1954), p. 257-260).

(14) En nuestro Derecho como lo señalaba Couture (o cit. nota anterior) no existe medio "procesal idóneo para decidir in limine litis este presupuesto procesal" (p. 260). En el Derecho Brasileño, por el contrario está consagrado el instituto del "despacho saneador", "por medio del cual decide el Juez cuestiones relativas a la legitimidad de la relación procesal. De este modo puede ordenar la supresión oportuna de los vicios subsanables y extinguir, al nacer, procesos de constitución maculada por defecto irremediable - no subsanado" (Galeno Lacerda "Despacho Saneador", Porto Alegre 1953, p. 6; cfr. p. 57 y sigs.).

(15) Couture "El agotamiento..." cit. pág. 260. 
cia de una sentencia favorable, es decir, presupuestos para que sea acogida la demanda (la acción) en la sentencia (por la jurisdicción).

En el caso, podría hablarse de presupuesto formal, o de admisibilidad (procesal) de la pretensión o de la demanda. - Con respecto a la sentencia se trataría de presupuesto no para que pueda (formalmente) dictarse sentencia, sino para adoptar resolución sobre el fondo del asunto (máterial ó sustancialmente).

Por tanto si no se realizó el acto administrativo o si éste no es definitivo (no se interpusieron contra él, en tiempo y forma, los re. cursos administrativos respectivos) no cabe sentencia sobre el asunto de fondo; la que recaiga deberá declarar la inadmisibilidad de la de manda de anulación (16).

En cuanto al objeto de la sentenciá está delimitado por la Constitución: declarar si es ilegal el acto administrativo. "el objeto del proceso es siempre la legalidad del acto administrativo impugnado, "en sentido amplio, jurisdicidad del acto administrativo definifivo" (17). Estamos en el campo típico y tradicional de la jurisdicción: decir el derecho, "jus dicere".

No es preciso recordar que para resolver esta "quaestio juris", el Tribunal deberá tomar en cuenta la "quaestio facti". - Conviene subrayar que la situación no es la que plantean los casos en que el Superior está vinculado por la resolución dada a la última por el Inferir, quedando limitada su fiscalización al problema de derecho, posición típica del recurso de tasación o (parcialmente) del recurso extraordinario de nulidad notoria en cuanto a la forma. - La razón ès clara, pues, se trata de la intervención (originaria y única) de un Tribunal con respecto de una actividad que se realiza fuera de su órbita y las dos cuestiones integran, por esencia, el problema a resolver: hay que determinar qué se hizo (acto), con respecto a qué (sobre qué recayó el mismo), para saber si se ajusta o no al sistema jurídico. La exclusión del problema de hecho se explica en aquellos casos, por cuanto ya hubo pronunciamiento, - que se considera definitivo -, órgano jurisdiccional competente (18).

En consecuencia, si bien a menudo la deferminación de lo acontecido se agota con la agregación del expediente administrativo, pue-

(16) Goldschmidt ("Derecho Procesal Civil", trad. Prieto Castro) dice que "los presupuestos procesales no lo son en realidad del proceso; son simplementa presüpứestos, requîsifos previos de la sentencia de fondo sobre los que se resuelve en el proceso". (p. 8). Puede hablarse también de "presupuestos de la acción procesal" en el sentido de "requisitos de la tútela jurídica" (p. 97). Pero en sentido estricto los llamados desde Bülow presupuestos procesales son "condiciones que se exigen para la admisibilidad de la demanda", " "mejor aún, presupuestos, requisitos de la sentencia de fondo" (p. 242).

(17) Informe de la Comisión de Constitución de la C. de Representantes, en Martins-Gros Espiell, o. cit., págs. 120 y 121.

(18) En el proceso moderno, dice Calamandrei, propuesta la demanda "el juez se encuentra... colocado ante dos problemas: 10 ¿Son verdaderos los hechos que la parte afirma? 2.0 Deriva de estós hechós el efecto jurídico que ta parte pretende" ("La génesis lógica de la sentencia civil", N.0 4. En "Estudios sobre el proceso civil", trad. Sentis Mélendo pág. 374). 
de corresponder también, la utilización de otros medios de prueba, particularmente cuando se trata de demostrar la "desviación de poder".

La fiscalización de la juridicidad, por otra parte, lo es de la legalidad, no de la constitucionalidad, por cuanto ésta corresponde privativamente a la Suprema Corte de Justicia (arts. 256, 261 de la Constitución).

El problema de la causa no presenta tampoco aspectos especiales a considerar. - La doctrina talvez dominante (19) considera que el recurso de anulación es precedente necesario al juício de reparación ante la justícia Ordinaria, de acuerdo con el art. 312 de la Constitución: "declarada la anulación o reservada la acción de reparación en su caso, se podrá promover el contencioso de reparación ante la justicia ordinaria, para la determinación del daño causado". - Pero aún en la opinión contraria (20) que concede al interesado la facultad de elegir libremente entre una u otra vía, no habrá problemas, en el tema a que nos referimos -, pues elegido el contencioso de reparación, cualquiera fuera el resultado obtenido, ya habría caducado la facultad de solicitar la anulación por el transcurso de los plazos para recurrir.

Por último, conviene subrayar que la competencia del Tribunal se amplía, cuando se trata del "contencioso inter - administrativo", , sues en tal caso, sin limitaciones, se le atribuye, además de intervenir "en las contiendas de competencia fundadas en la legislación", también "en las diferencias que se suscitan entre el Poder Ejecutivo, los Gobiernos Departamentales, los Entes Autónomos y los Servicios Descentralizados y también en las contiendas o diferencias entre uno y otro de estos órganos" (art. 313, inc. 1).

Además se le atribuye el llamado contencioso "de integración"; también entenderá en las contiendas o diferencias que se produzcan entre los mismos integrantes de los Consejos y Juntas Departamentales, Directorios o Consejos de los Entes Autónomos o Servicios Descentralizados, siempre que no hayan podido ser resueltas por el pro. cedimiento normal de la formación de la voluntad del órgano" (art. 313, inc. 2). - En tal caso, el Tribunal llega a ejercer la función administrativa, resolviendo el problema que correspondía al órgano que quedó paralizado en el proceso de formación de su voluntad. - El procedimiento sirve aquí para aportar al Tribunal los datos ilustrativos que requiere para determinar la solución no sólo más justa sino, además, más conveniente para la administración: el fin no es sólo el derecho sino el interés de la buena administración.

(19) E. Sayagués Laso (o. cit. p. 70); "se organiza el contencioso de anulación con carácter previo y como condición a la ulterior reparación"; la Justicia ordinaria en materia de reparación solo podrá entender "a consecuencia de la declaración de nulidad (anulación o reserva)... por el Tribunal", dice Barrlos de Angelis (o. cit. p. 25 y 26).

(20) A. Méndez (o. cit. p. 77): "no cabe imponer el procedimiento anulatorio al interesado (y) tampoco es posible impedir si transcurrió el término... para accionar en esa via, el ejercicio de cualquier otra jurisdicción". 
E) En principio, los discutidos problemas de la condición, serán de aplicación a la sentencia asignada y su función de fiscalizador de la legalidad, puede decirse que aún más claramente que en los casos habituales, parece repugnar a la sentencia el que sus efectos estén sujetos a condición.

Sin embargo, nos permitimos subrayar una circunstancia importante. - La ejecución puede y suele considerarse en el plano de la acción (¿continuidad de la acción principal o actio judicati?), de la jurisdicción (¿esencial o no a dicha función?), del proceso (unidad o diferenciación con el de conocimiento? y jerarquía entre los mismos), del procedimiento (etapas, sumariedad, etc.); - puede encararse, también, desde el punto de vista de la teoría de los actos. - En el caso de la sentencia cabría entonces hablar de la ejecución típica como un medio para lograr la (imperativa y aún coercitiva) consumación del acto; cuando la ejecución no se lleva a cabo, éste se frustra.

Cuando se trata de la sentencia anulatoria del Tribunal, el problema que se presenta (como siempre que se procura hacer cumplir una resolución judicial por parte de la Administración a lo cual se ponen obstáculos prácticos y aún legales (21) es cómo lograr, con eficacia, que lo resuelto por la Justicia se convierta en realidad administrativa.

Pero no se trata sólo del problema de cumplimiento o incumplimiento de la resolución jurisdiccional, que en buena parte depende de la educación jurídico - política de los habitantes del Estado y del respeto que exista entre los diversos organismos públicos por sus correspondientes esferas de influencia, sino que, desde el punto de vista jurídico estricto, pueden ser necesarios ciertos actos para que aquel resultado se alcance. V. gr.: restitución de un bien ocupado ilegalmente (acto material de entrega, siempre; normalmente acto jurídico, por lo menos interno de la Administración, ordenando a los funcionarios respectivos la realización de la entrega), anulación de la distitución (reposición del empleado; señalamiento de destino; restitución de sueldos); anulación del nombramiento (reposición de las cosas en el estado anterior-; etc.

Prácticamente, en caso de desobediencia, habrá que acudir al "uso de apremios o medidas conminatorias, con que los jueces hacen cumplir sus determinaciones" (22) y no existiendo en el Derecho Uruguayo, para el caso, disposiciones asimilables al "contempt of court" anglo saión o a la "astreinte" franco - belga, no correspondería aplicar ese tipo de soluciones (23). - Procede, en cambio, en su caso, poner en

(21) Couture en su "Proyecto de Código de Procedimiento Civil", (1945) establecia que las sentencias contra el Estado se ejecutarían ante la Suprema Corte; en caso de condena al pago de cantidad de dinero, el Banco de la República pondría la suma a la orden de la Corte, debitándola, en la cuenta del Estado (art. 461).

(22) R. Molina Pasquel, "Contempt of Court", pág. 21.

(23) Gelsi, "Medios indirectos de ejecución de las sentencias: contempt of court y, astreintes" ("La Revista de Derecho, Jurisprudencia y Administración", tomo 50 (1952) - págs. 92-93). 
movimiento la justicia represiva penal, por medio de denuncia, pues los funcionarios administrativos que no cumplan la resolución del Tribunal incurrirán en el delito de desacato, que el C. Penal uruguayo tipifica (en lo pertienente) como sigue: "Se comete desacato, menoscabando la autoridad de los funcionarios... por medio de desobedien. cia abierta al mandato de los mismos" - "El delito se castiga con 3 a 18 meses de prisión" (art. 173). - Este camino, junto con el de denuncia al Poder Ejecutivo (que puede observar y aún proponer correctivos y destituciones al Senado, art. 199 de la Constitución), fue el seguido por el Tribunal en un resonante caso (no publicado aún en revistas jurídicas) frente a los miembros del Directorio de un Ente Autónomo.

\section{IV}

\section{Naturaleza de la sentencia.}

12) Desde el punto de vista subjetivo no reviste dificultades la categorización de la sentencia. - Se trata de un acto simple, pues se debe al único órgano que constituye el Tribunal; ya se dijo que la intervención del Proçurador del Estado es al sólo efecto informativo y que no integra la decisión.

Tampoco existe real conexión con las autoridades administrativas: la decisión se realiza en un plano diverso, en ejercicio de función dife. rente y enjuiciando el acto de aquéllas, no integrándose con el mismo. - La sentencia que declara la ilegalidad, está evidentemente en dicha situación. - Pero lo propio ocurre con la que no la considera existente y que, por tanto, en la terminología constitucional, lo "confirma" "art. 310). - En el fondo se trata simplemente de declarar, con fuerza de cosa juzgada - , la regularidad legal del acto; esa declaración no se añade al acto como algo nuevo, que va a formar unidad con aquél; es un acto diferente, que responde a una función jurídica diversa y si algo le agrega es, - desde fuera -, una mayor seguridad o garantía de la juridicidad, una especie de "patente" de tal, que habrá de jerar quizarlo en el comercio jurídico. - Lo cual se da en todos los casos de declaración judicial del derecho.

La existencia de una pluralidad de integrantes, - no es necesario recordarlo -, en nada modifica la şituación. - Se trata siempre del mismo órgano, aunque pueda requerirse integración diversa (de votantes o de votos conformes) según la naturaleza del acto o el objeto del mismo confirmación, tres votos; anulación, cuatro; reserva de la acción de reparación, tres.

13) Si se atiende a la función que se concreta en el acto subexamen como surge de lo que precede es claro que se trata de un acto juriśdiccional. - Más aún, si se toma en cuenta el tipo de actividad ejercida, obviamente se clasifica entre las sentencias, pudiendo el Tribunal dictar interlocutorias o definitivas en iguales oportunidades que los restantes órganos jurisdiccionales. 
"La decisión del Tribunal de lo Contencioso-Administrativo, - dice el Informe de la C. de Constitución -, ę una sentencia - Esa sentencia, ejercicio de función jurisdiccional especial, es suceptible de pasar en autoridad de cosa juzgada" (24) característica que muchos consideran típica del acto jurisdiccional o, por mejor decir, de ciertas decisiones jurisdiccionales, al menos en nuestro sistema jurídico. "La eficacia y estabilidad de las resoluciones judiciales, - dice Podetti -, derivan de un principio formal y no material. - Surgen del proceso y se oponen dentro del proceso... y se encuentran limitados por normas procesales (... efectos inter omnes o sólo inter partes o que no hacen cosa juzgada)" (25).

14) Analizando el acto objetivamente, puede decirse como de casi todas las sentencias que se trata de un acto complejo pues se presentan en unidad, varias decisiones que solucionan problemas diferentes, aunque esencialmente vinculados en el mismo proceso.

Normalmente toda sentencia contiene dos resoluciones, por lo menos. - Una sobre la cuestión disputada y otra sobre el problema del pago de los gastos procesales (a cuál de las partes corresponde). Tema que en nuestro derecho puede revestir cierta complejidad, pues debe tenerse presente, en disparidad con el sistema dominante: a) Que el principio no es que pague el vencido, sino cada parte los que correspondan según el orden en que se hubieren causado; la imposición de las costas se establece en base a la conducta que en el proceso hubieren observado las partes, constituyendo, por ende, una típica sanción procesal con influencia en el dominio fiscal. - b) Que los gastos procesales se subdividen en costas y costos, según que sei encuentren o no arancelados (art. 688 del C. Civil). - Este sistema del Derecho Procesal común, rige tambien para el proceso contencioso-administrativo.

En el caso de esta sentencia, puede concurrir aún una situación peculiar. - Cuando no se alega la lesión a un derecho subjetivo, se requieren 4 votos para declarar la nulidad pero, "sin embargo, el Tribunal reservará a la parte demandante, la acción de reparación, si 3 votos conformes declaran suficientemente justificada la causal de nulidad invocada" (art. 310, inc. 3). - Esta reserva de la acción de reparación, como dice Méndez, es en realidad una verdadera condena al pago de los perjuicios caugados (26) pues, como precisa el art. 312, "reservada la acción de reparación. . . se podrá promover el contencioso de reparación ante la justicia ordinaria para la determinación del daño causado". - En definitiva, el "an debeatur" correspondería al Tribunal.y el "quantum debeatur" a la justicia ordinaria (v. infra 17-A).

(24) "Informe de la Comisión de Reforma" de la C. de Representante (Martins-Gros Espill o cit. p. 121).

(25) Podetti "Teoria y técnica del proceso civil", pág. 78.

(26) A. Méndez (o. cit., pág. 25): en tal caso procede pedir a la justicia ordinaria "la liquidación de los daños y perjuicios, de conformidad con el procedimiento para la ejecución de las sentencias". 
Se desglosan en tal sentencia, las decisiones relativas a la ilegalidad del acto y a sus consecuencias. Si se rechaza la demanda, sólo existe esa cuestión y lo mismo si se acoge pura y simplemente. - Pero hay una segunda, que normalmente corresponde a la justicia ordinaria y sólo indirectamente al Tribunal y que en este caso se atribuye a éste: resolver en cuanto a la reparación, aunque sin determinar su monto. - Por ende, aunque se emiten en forma conjunta y constan en el mismo documento, cabe analizarlo (desde el punto de vista de lacto como emisión de voluntad) en una variedad de resoluciones, que podrían darse separadamente.

\section{$\mathrm{V}$}

\section{- Efectos}

15) El problema de los efectos de la sentencia se encuentra estrechamente liado con el anterior y algunos de sus aspectos podrían estudiarse en éste; se consideran aquí, siguiendo el planteamiento corriente. Deliberadamente se establecen como efectos de la sentencia y no de la cosa juzgada, que estimamos ser aspecto, calidad o característica, adquirida por aquélla (27).

Los límites subjetivos de la eficacia del acto son establecidos por el art. 311: "Cuando el Tribunal declare la nulidad del acto administrativo impugnado por causar lesión a un derecho subjetivo del demandante, la decisión tendrá efecto únicamente en el proceso en que se dicte" (inc. 1). - "Cuando la decisión declare la nulidad del acto en interés de la regla de derecho e de la buena administración, producirá efectos generales y absolutos" (inc. 2). - Disposición que requiere algunas aclaraciones.

El principio en Derecho Procesal, es que la sentencia sólo afecta a las partes para las que fué pronunciada, de modo que los terceros pueden ampararse en la regla "res inter alios judicatae, alii non praeiudicant". Se trata, en el fondo, de la delimitación del proceso, por aplicación del principio del contradictorio (con el "legítimo contradictor) o ,desde otro punto de vista, del principio de la (debida) defensa en juicio: nadie puede ser condenado sin haber sido previamente convocado a juicio y (eventualmente) oído en él. - De ahí que la fórmula del inc. 1 deberá interpretarse: "tendrá efecto únicamente (entre las partes) en el proceso, pues incluso las afectará fuera del mismo (cosa juzgada material).

Esa limitación como regla, puede tener excepciones. A veces derivan de razones de derecho sustancial, por la relación de terceros con la cuestión decidida ( $v$. gr. deudores solidarios; o legatarios en el caso de nulidad de testamento pronunciada contra el heredero). - En otras, se trata de un problema de legitimación: se estima que el liti-

(27) Siguiendo a Liebman en cuanto a no tratar a la cosa juzgada como efecto de la sentencia ("Eficacia y autoridad de la sentencia" trad. Sentis Melendo p. 57 y 70). 
gante puede actuar y actúa por todo un conjunto de sujetos ( $v$. gr. un gremio (28).

En otros casos, como en el artículo transcrito, la eficacia es general ("erga omnes") y absoluta (no condicionada ni relativa a otro factor) en virtud de interés afectado. - En realidad no existe oposición entre los dos incisos; puede lesionarse un derecho subjetivo y además, el interés de la regla de derecho o de la buena administración (29). - El constituyente seguramente quiso decir, en el ler. inc., "úni camente" el derecho del demandante, para contraponer el caso en que sólo se afecta el interés de los litigantes, de aquél (inc. 2) en que se lesiona un interés más calificado. - Calificación que, - prácticamente - , se remite a la mayor extensión o presunta afectación generalizada: el interés de la ley (que por esencia, en su sentido material es mandato de carácter universal) o el de la buena administración. - En el primer caso, el interés es más impersonal; en el $2 .^{\circ}$, aunque referible a la "Administración" se supone que, a través de ella, alcanza a un conjunto de sujetos.

En conclusión, la sentencia tendrá efectos "inter partes" como principio y para todos, cuando la ilegalidad afecte los intereses calificados aludidos $y$, por tanto, en virtud de la relación existente entre el acto objetivamente (en sí) considerado y dichos intereses.

16) El problema temporal no ha recibido previsión especial en la Constitución y queda, por tanto, sujeto a la aplicación de los conceptos del Derecho Procesal común, estrechamente ligados a la categorización de la sentencia segun su efecto sobre el derecho o,meior la situación (jurídica) decidida.

Cabe, sin embargo, señalar que la función del llamado "contencioso de anulación" de eminente garantía frente a posibles desviaciones de la legalidad por parte de la Administración, que tiene por finalidad principal mantenerla dentro de los cauces legales, no se alcanzaría adecuadamente si sus efectos no comenżaran a partir de la fecha en que el acto fue emitido.

De prevalecer la tendencia que considera que el Tribunal declara - fundamentalmente -, la ilegalidad y no constituye una nueva si. tuación jurídica, sino que pone de manifesto la oposición del acto con la ley que debería aplicar, - no cabría duda de la vigencia temporal de las consecuencias que surgen de la aludida declaración: desde la fecha de pronunciamiento del acto impugnado.

17 A - Dice la Comisión de Reforma de la C. de Representantes que tratándose de una sentencia, que es ejercicio de función jurisdiccional, y "susceptible de pasar en autoridad de cosa juzgada", "esa sentencia produce efectos obligatorios respecto a todo otro Tribunal, en

(28) Moretti "Naturaleza de los laudos de los Consejos de Salarios" (en "Derecho Laboral" t. 5.․ 1950) p. 206.

(29) Cfr. Pereira Anabalon, o. cit. p. 12. 
cuanto ningún otro Tribunal puede dictar otra sentencia igual o distinta a la pronunciada por el Tribunal de lo Contencioso-Administrativo" (30).

No es necesario agregar la consecuencia que la decisión de tal cuestión tiene sobre los actos a realizar por la Administración Central, - Descentralizada que intervino en el litigio, e incluso la que, aún no habiendo actuado en el proceso, debe verificar actividad indispensable para la ejecución de lo resuelto por el Tribunal: "Para hacer ejecutar sus sentencias... pueden los tribunales requerir de las demás autoridades el concurso de la fuerza pública que de ella dependa, o los otros medios de acción conducentes de que dispongan. La autoridad requerida en forma debe prestar su concurso. .." (at. 5. ${ }^{\circ}$ del C. de Organización de los Tribunales). - Tal imperatividad de la sentencia se actúa dentro de los límites de la "res" planteada y resuelta en el proceso.

Conviene subrayar que la declaración de ilegalidad que pronuncie el Tribunal tendrá plena eficacia incluso en el juicio de reparación que se promueva ante la justicia ordinaria (art. 312. - Solución acertada, por cuanto si bien la finalidad mediata perseguida, es diversa en ambos casos (inaplicabilidad del acto o reparación por los daños causados), sin embargo, la cuestión jurídica resuelta en el primero (si el acto es ILEGAL), integra la del $2 .^{\circ}$ (daño causado, por acto administrativo, al interés legítimo de un sujeto, CONTRAVINIENDO el sistema JURIDICO). - En el segundo, las consecuencias pueden ser diversas, pero una de las premisas es idéntica.

B - Tal vez uno de los problemas más discutibles es el de determinar si la sentencia del Tribunal debe considerarse, en cuanto al efecto sobre la situación jurídica en cuestión, declarativa, constitutiva o de condena.

Reviste esta última condición cuando (y en cuanto) a las sanciones procesales, si las impone', o cuando reserva la acción de reparación, es decir, condena al pago de los daños que se hubieran causado.

Habitualmente la cuestión se propondrá entre las dos primeras calificaciones. - La Constitución habla de "declarar la nulidad del acto impugnado" (a. 310, inc.), de "pronunciar (término más ambiguo) la nulidad" (inc. 3); en el art. 311 usa dos veces la expresión "declare la nulidad del acto administrativo"; "declarada la nulación, - dice el $312-, \ldots$ se podrá promover el contencioso de reparación".

A este argumento tomado de la letra de la ley, debe añadirse un segundo, teleológico en el sentido de que la naturaleza constitutiva de la sentencia no respondería al sistema de garantías contencioso - administrativas.

Tal observación tiene mayor trascendencia que las que habitual-

(30) Informe de la Comisión de Reforma de la C. de Representantes, loc. cit. nota (24). 
mente se plantean en ese plano por cuanto aquél ha sido estructurado de modo paralelo con el contencioso de inconstitucionalidad y respondiendo también a la finalidad de mantener la jerarquía de las normas. - Inconstitucionalidad: prevalencia de la Constitución sobre la ley; ilegalidad: preferencia de la ley sobre los actos administrativos que deben aplicarla. Cualesquiera sea la teoría que se entienda más acertada, todas admiten la existencia de un distinto valor jurídico entre unos y otros mandatos, en el sentido de que unos disponen ciertos cauces que no pueden ser abandonados por los otros; en el caso del acto administrativo, sólo le corresponde desenvolver, precisar pero siempre aplicar la ley respectiva. - De tal manera que el administrado que se encuentre ante una ley y un acto administrativo contradictorios, puede (y debe) atenerse a la primera.

Las consecuencias de esta declaración de nulidad son las obvias en un proceso contencioso - administrativo de (defensa de la) legalidad: si el acto es legal se le confirma, es decir, de declara que es legal, en realidad: se rechaza la demanda de ilegalidad. - Si es ilegal, e acto es inaplicable en el proceso, e incluso "erga omnes" em la situación ya estudiada (a. 311 , inc. 2). - Sin embargo, por la vía del quorum especial para la declaración de nulidad con efectos anulatorios, si no se lesiona derecho subjetivo, el acto se mantiene, pero el Tribunal debe reservar la acción de reparación (condena preceptiva en el supuesto de la declaración de ilegalidad por tres votos conformes).

La Comisión de Reforma de la C. de Representantes (31 aludiendo a estas dos situaciones, las califica de contencioso "de anulación", que "es el contencioso administrativo tipo" y "de ilegalidad sin anulación con reserva de la acción de reparación", que sería el "atípico o anómalo" (32).

Aunque la letra Constitucional nada establece al respecto y aparentemente toda ilegalidad provocaría la inaplicabilidad del acto, el tantas veces citado Informe añande que "aunque el Tribunal comprue. be el vicio que invalida al acto jurídico - administrativo, puede mante ner el acto impugnado en dos hipótesis: 1) si la causal de nulidad no es lo suficientemente grave para declarar la nulidad; 2) si la declaración de nulidad causara daños graves e irreparables" de mayor entidad que los que puedan producirse con el mantenimiento del acto". - Comprendemos que el primer caso es admisible aún en contencioso de ilegalidad, pues esta tiene varios grados y entre ellos los hay de tan escasa monta que no cabe pensar que provoque la inaplicabilidad del acto. - El $2 .^{\circ}$, en cambio, no está autorizado por la letra constitucional ni se compagina directamente con el sistema de defensa de la legalidad.

(31) Informe de la Comisión de Reforma de la C. de Representantes, loc. cit.

(32) Nos inclinamos, pues, por la naturaleza declarativa, (si bien el punto se presta a dudas particularmente en ciertos casos de nulidad propiamente dicha) en cuanto al problema planteado sub B, sobre el cual esperamos volver en otra oportunidad. 
C - El texto constitucional al calificar el contencioso consagrado, habla de "demandas de nulidad... de actos (de)... la Administración. . . contrarios a una regla de derecho o con desviación de poder" (a. 309, inc. 1) y de "acción de nulidad" (a. 309, inc. 3; a. 319; Disp. Trans. $\mathrm{N} \mathrm{5.} .^{\circ}$ ). Cuando menciona el contenido de la sentencia con referencia al acto impugnado expresa: "el Tribunal se limitará a apreciar el acto en sí mismo, confirmándolo o anulándolo, sin reformarlo" (a. 310, inc. 1); "declarar la nulidad" (a. 310, inc. 2; cfr. a. 311) o "pronunciar la nulidad" (art. 310, inc. 3) y en otro art.: "declarada la anulación" (art. 312).

Es un "contencioso de anulación", pues, como también lo denominan los comentadores (33) pero el sentido de nulidad o de anulación, excede aquí a la noción estricta que suele darse en el plano procesal y aún sustantivo, a tales términos (34).

Se ha querido señalar un aspecto negativo: el Tribunal no tiene competencia para sustituir el acto impugnado ("anulándolo, sin reformarlo", a. 310, inc. 1); la consecuencia práctica es meramente la de suprimir el acto (tenerlo imperativa y definitivamente por suprimido, si la sentencia es declarativa).

No cambia la situación, el hecho de una extensión mayor o menor de los límites subjetivos. - Estos (como ya se dijo) derivan, en princípio, de la estructura procesal; la Constitución los amplía, en ciertos casos, por afectar el interés de la buena administración o de la regla de derecho (el sistema objetivo de Derecho): aquí la "supresión" se hace más efectiva y total.

La ilegalidad abarca toda suerte de desviaciones, que tanto pueden configurar la nulidad propiamente dicha como la injusticia, de manera similar a lo que ocurre en el recurso de casación. - Sí se quisiera caracterizar las consecuencias generales de esa declaración de ilegalidad, podría hablarse o bien de supresión (para las partes o para todos) del acto o de inaplicabilidad del mismo en el caso planteado o en todo otro que se presente. - Naturalmente que aduciendo la omnipotencia legislativa en la materia, podría el legislador o el constituyente establecer la ley como acto - antecedente necesario (presupuesto) del administrativo, que en caso de faltar daría lugar a nulidad de este último acto.

(33) Por ej. A. Méndez, en el libro cit.

(34) Gelsi "De la nulidades en los actos procesales", v. gr. p. 287. A menos que, como lo hace el C. Proc. Civil del Uruguay se hable de una nulidad de fondo que no es sino la injusticia; cfr. id. p. 145-49. 